\title{
Identification of Binding Regions of Bilirubin in the Ligand-Binding Pocket of the Peroxisome Proliferator-Activated Receptor-A (PPARalpha)
}

\author{
Darren M. Gordon ${ }^{1}$, Stephen H. Hong ${ }^{1}{ }^{(}$, Zachary A. Kipp ${ }^{2}$ and Terry D. Hinds Jr. ${ }^{2, *}$ \\ 1 Department of Neurosciences, University of Toledo College of Medicine and Life Sciences, \\ Toledo, OH 43614, USA; Darren.Gordon@rockets.utoledo.edu (D.M.G.); \\ Stephen.Hong@rockets.utoledo.edu (S.H.H.) \\ 2 Department of Pharmacology and Nutritional Sciences, University of Kentucky College of Medicine, \\ 760 Press Avenue, Healthy Kentucky Research Building, Lexington, KY 40508, USA; Zachary.Kipp@uky.edu \\ * Correspondence: Terry.Hinds@uky.edu
}

Citation: Gordon, D.M.; Hong, S.H.; Kipp, Z.A.; Hinds, T.D., Jr. Identification of Binding Regions of Bilirubin in the Ligand-Binding Pocket of the Peroxisome Proliferator-Activated Receptor-A (PPARalpha). Molecules 2021, 26, 2975. https://doi.org/10.3390/molecules 26102975

Academic Editor: Anna Cleta Croce

Received: 9 April 2021

Accepted: 12 May 2021

Published: 17 May 2021

Publisher's Note: MDPI stays neutral with regard to jurisdictional claims in published maps and institutional affiliations.

Copyright: (c) 2021 by the authors. Licensee MDPI, Basel, Switzerland. This article is an open access article distributed under the terms and conditions of the Creative Commons Attribution (CC BY) license (https:// creativecommons.org/licenses/by/ $4.0 /)$.

\begin{abstract}
Recent work has shown that bilirubin has a hormonal function by binding to the peroxisome proliferator-activated receptor- $\alpha(\operatorname{PPAR} \alpha)$, a nuclear receptor that drives the transcription of genes to control adiposity. Our previous in silico work predicted three potential amino acids that bilirubin may interact with by hydrogen bonding in the PPAR $\alpha$ ligand-binding domain (LBD), which could be responsible for the ligand-induced function. To further reveal the amino acids that bilirubin interacts with in the PPAR $\alpha$ LBD, we harnessed bilirubin's known fluorescent properties when bound to proteins such as albumin. Our work here revealed that bilirubin interacts with threonine 283 (T283) and alanine 333 (A333) for ligand binding. Mutational analysis of T283 and A333 showed significantly reduced bilirubin binding, reductions of $11.4 \%$ and $17.0 \%$, respectively. Fenofibrate competitive binding studies for the PPAR $\alpha$ LBD showed that bilirubin and fenofibrate possibly interact with different amino acid residues. Furthermore, bilirubin showed no interaction with PPAR $\gamma$. This is the first study to reveal the amino acids responsible for bilirubin binding in the ligand-binding pocket of PPAR $\alpha$. Our work offers new insight into the mechanistic actions of a well-known molecule, bilirubin, and new fronts into its mechanisms.
\end{abstract}

Keywords: autofluorescence; heme oxygenase; HO-1; biliverdin reductase; BVRA; albumin; bilirubin; PPAR; nuclear receptor; mutagenesis analysis

\section{Introduction}

The peroxisome proliferator-activated receptors (PPARs) are a class of nuclear receptors that have become major targets for addressing various metabolic disorders, including lipid dystrophies and diabetes [1]. PPARs are nutrient receptors that have various selective and promiscuous ligands, including fatty acids and eicosanoids. There are three major isoforms of PPARs: PPAR $\alpha, \operatorname{PPAR} \beta / \delta$, and PPAR $\gamma$. PPAR $\alpha$ and PPAR $\beta / \delta$ induce genes to regulate lipid uptake and metabolism [1-3]. PPAR $\gamma$, which is additionally stimulated by thiazolidinediones (TZDs; rosiglitazone, pioglitazone) [4], induces transcription of genes involved in fat storage and lipogenesis $[1,2,5]$. These nuclear receptors play key roles in regulating cellular metabolism, which results in phenotypic changes such as improved glucose storage and reduced serum lipids. Therefore, understanding the ligand-binding capability of these nuclear receptors is important in appreciating the pharmacokinetics of newly developed compounds that target obesity and diabetes. In our previous work, we found structural similarities between bilirubin, the red blood cell metabolite, and known ligands of PPAR $\alpha$ [3]. Furthermore, clinical phenotypes associated with mildly elevated bilirubin levels are associated with reduced adiposity, suggesting an interaction between PPAR $\alpha$ and bilirubin. We have previously addressed this binding interaction by quanti- 
fying the binding modalities between bilirubin and PPAR $\alpha$ [6], which was achieved via fluorescent-based assays similar to the well-known bilirubin albumin autofluorescence.

The autofluorescence phenomenon is only demonstrated when bilirubin was bound to protein (albumin), and either alone did not display these properties [7-10]. When bilirubin binds albumin and is excited by light, it undergoes a conformational change $(Z \rightarrow E$ configuration). This configuration, now photobilirubin/lumirubin, allows for greater mobility of the pyrrole rings and subsequent emission behavior [11-13]. Utilizing this property of bilirubin to fluoresce when bound to proteins, aside from albumin, is a new concept to explore binding interactions. In this study, we explore the binding capability of bilirubin to the PPAR $\alpha$ ligand-binding domain (LBD) using bilirubin's autofluorescent properties. Various studies have explored the binding capabilities of known ligands to PPARs using fluorescence or radioactive means of measurement [14-16]. Other studies have shown that bilirubin induces fluorescent properties by interacting with the fluorescent protein UnaG protein from eel muscle $[17,18]$. Our study here focused on the intrinsic properties of bilirubin to autofluoresce when excited by light and bound to protein, specifically PPAR $\alpha$ and mutations in amino acids of the LBD that may be responsible for bilirubin binding. Ultimately, investigation of this interaction will highlight the role of bilirubin as a metabolic hormone to activate nuclear receptors, resulting in phenotypic improvements in metabolism (discussed further in our extensive review [19]).

We found that bilirubin bound to albumin autofluoresces in a dose-response relationship and show bilirubin bound to PPAR $\alpha$ autofluoresces in a similar manner. We present bilirubin's binding capacity with specific amino acids in the PPAR $\alpha$ LBD and show that this can be quantitated based on its autofluorescence.

\section{Materials and Methods}

\subsection{Reagents}

Phosphate-buffered saline (PBS) (Amresco, Solon, OH, USA), bovine serum albumin (BSA) (Fisher Scientific, Hampton, NH, USA), unconjugated bilirubin (Frontiers Scientific, Logan, UT, USA), and dimethyl sulfoxide (DMSO) (MP Biomedicals, Solon, OH, USA).

\subsection{Cell Culture}

Human Embryonic Kidney 293 (HEK293) cells were routinely cultured and maintained in Dulbecco's Modified Eagle Medium (DMEM) containing 10\% FBS with 1\% penicillin-streptomycin.

\subsection{Full-Length Histidine-Tagged PPAR Construction}

Full-length histidine-tagged mouse PPAR $\alpha$ and PPAR $\gamma$ sequences were amplified with designated primer for restriction enzymes as listed in the table below using the KOD Hot Start DNA polymerase kit (Millipore Sigma, Burlington, MA, USA). A 1\% agarose gel verified the presence of a single band of the PPAR at $\sim 1.5 \mathrm{~kb}$, which was purified using the Qiagen Gel extraction (Qiagen Biotechnology, Hilden, Germany). Primer sequences for cloning PPAR $\alpha$ were forward-containing BamHI restriction sites (5'-CGGGATCCGATGGTGGACACAGAGAGCC- $\left.3^{\prime}\right)$ and reverse-containing XbaI restriction sites (5'-GCTCTAGACTCTTCATCCCCAAGCGTAG-3'). Primer sequences for cloning PPAR $\gamma$ were forward-containing KpnI restriction sites (5'-GGGGTACCTTATGGGTGAAACTCTGGGAGAT-3') and reversecontaining XbaI restriction sites (5'-GCTCTAGAAGAAGGAACACGTTGTCAGC-3'). The PCR products and the pcDNA6/His A vector (Invitrogen, Carlsbad, CA) were digested with the appropriate restriction enzymes described in the table below for each respective isoform overnight at $37^{\circ} \mathrm{C}$. A $1 \%$ agarose gel verified the presence of a single band at approximately $5.2 \mathrm{~kb}$ for the pcDNA6HisA vector, which was purified using the Qiagen Gel extraction kit. The PPAR $\alpha$ or PPAR $\gamma$ PCR products were purified using the Qiagen PCR purification kit (Qiagen Biotechnology, Hilden, Germany). Ligation of the pcDNA6/HisA vector and the PPAR $\alpha$ or PPAR $\gamma$ PCR products was achieved using a Rapid Ligation kit (Thermofisher Scientific, Waltham, MA, USA) for $1 \mathrm{~h}$ at room temperature. The ligation 
product was transformed into DH5 $\alpha$ cells (Invitrogen, Carlsbad, CA, USA). Colonies were grown on $0.1 \%$ ampicillin fortified agarose plates overnight in a $37^{\circ} \mathrm{C}$ non- $\mathrm{CO}_{2}$ incubator. Individual colonies were selected and grown in LB broth with $0.1 \%$ ampicillin. The plasmid from selected colonies was isolated and purified using the Qiagen Mini-Prep kit (Qiagen Biotechnology, Hilden, Germany). Sequencing of the plasmids was performed using primers T7 forward (5'-TAATACGACTCACTATAGGG-3') and BGH Reverse $\left(5^{\prime}\right.$ TAGAAGGCACAGTCGAGG-3'). Successfully cloned colonies were grown in $500 \mathrm{~mL}$ of LB broth plus $0.1 \%$ ampicillin, and plasmids were extracted and purified using the Denville Spinsmart Maxi kit (Denville, Swedesboro, NJ, USA).

\subsection{PPAR $\alpha$ Ligand-Binding Domain Mutagenesis}

To determine the specificity of bilirubin-binding capacity with PPAR $\alpha$ in the ligandbinding domain, mutant proteins were created to target the sites previously shown to possibly hydrogen bond with PPAR $\alpha$ for optimal binding [3]. The mutant PPAR $\alpha$ A333G, M330G, and T283G were generated using QuikChange site-directed mutagenesis kit with the PPAR $\alpha$-pcDNA6/HisA plasmid according to the manufacturer's protocol (Stratagene, La Jolla, CA, USA). Primers for the mutant binding site were created using the QuickChange Primer Design program available on the Agilent website. The mutations were achieved using the QuikChange Lightning Site-Directed Mutagenesis Kit (Agilent, Santa Clara, CA, USA). Plasmids were transfected into XL 10-Gold Ultra Competent E. Coli cells and grown on a $1 \%$ ampicillin agar plate. Colonies were grown on $0.1 \%$ ampicillin fortified agarose plates overnight in a $37^{\circ} \mathrm{C}$ non-CO2 incubator. Individual colonies were selected and grown in L.B. broth with $0.1 \%$ ampicillin. The plasmid from selected colonies was isolated and purified using the Qiagen Mini-Prep kit. Confirmation of successful mutation was achieved via sequencing with Eurofins Genomics.

\subsection{Purification of PPAR Proteins}

Transient transfections were performed using GeneFect (Alkali Scientific Inc., Pompano Beach, FL, USA) in the HEK293 cells for 48 h. Cells were harvested via centrifugation and resuspended in $200 \mu \mathrm{M}$ HEPES. The His-Tagged proteins were extracted using the HisLink $^{\mathrm{TM}}$ Protein Purification Resin (Promega, Madison, WI, USA). Proteins were subsequently dialyzed overnight to remove excess elution compounds. The proteins were quantified using the BCA Protein Assay Kit (Thermofisher Scientific, Waltham, MA, USA). To confirm that the correct protein was purified, protein extracts were resolved by SDS polyacrylamide gel electrophoresis and electrophoretically transferred to Immobilon-FL membranes. Membranes were blocked at room temperature for $1 \mathrm{~h}$ in Odyssey Blocking buffer (LI-COR Biosciences, Lincoln, NE, USA). Subsequently, the membrane was incubated overnight at $4{ }^{\circ} \mathrm{C}$ with PPAR $\alpha$ (sc-1982), PPAR $\gamma$ (sc-7273), or His-Probe Antibody (sc-8036). After three washes in TBST (TBS plus $0.1 \%$ Tween 20), the membrane was incubated with an infrared anti-goat (IRDye 800, green) or anti-mouse (IRDye 680, red) secondary antibody labeled with IRDye infrared dye (LI-COR Biosciences) (1:15,000 dilution in TBS) for $2 \mathrm{~h}$ at $4{ }^{\circ} \mathrm{C}$. Immunoreactivity was visualized and quantified by infrared scanning in the Odyssey system (LI-COR Biosciences, Lincoln, NE, USA).

\subsection{General Autofluoresce Assay Setup}

In a black flat-bottom 96-well plate, stock BSA (final concentration $50 \mu \mathrm{M}$ ), stock PPAR $\alpha$ (final concentration 3-7.8 $\mu \mathrm{M}$ ), or PBS was added to the wells. Next, the test compound bilirubin was mixed into a well, repeated in triplicate, with the PBS, BSA, or PPAR $\alpha$. Once all compounds were added to the plate, the plate was protected with foil to avoid light degradation. Excitation and emission spectra of the samples were recorded using the top-read SpectraMax Plate Reader (Molecular Devices, San Jose CA, USA). The samples were read in $5 \mathrm{~nm}$ steps with both excitation and emission filters in use. The excitation spectrum was recorded from 300 to $495 \mathrm{~nm}$. Once the maximal emission for bilirubin bound to the albumin or PPAR $\alpha$ was recorded, then the wavelength of the peak 
value was set as the maximal excitation value and used for the excitation wavelength for the subsequent emission spectrum from 495 to $700 \mathrm{~nm}$.

\subsection{Statistics}

The data were analyzed via Prizm 8 GraphPad Prism version 8.00 for Mac (GraphPad Software, La Jolla, CA, USA) using analysis of variance combined with Tukey's post-test to compare pairs of group means or unpaired $t$-tests. Additionally, one-way ANOVA with the least significant difference post hoc test was used to compare mean values between multiple groups. Results are shown as the mean \pm S.E.M. $p$ values of 0.05 or smaller were considered statistically significant.

\section{Results}

\subsection{Autofluorescent Properties of Bilirubin and Biliverdin When Bound to Albumin}

Studies have shown that bilirubin autofluoresces when bound to albumin [9-11]. This relationship has been studied for decades due to albumin's regulation of free small molecule and protein concentration in the plasma. Work on the bilirubin-albumin interaction has shown that bilirubin emits its maximum fluorescence at $520 \mathrm{~nm}$ [9]; therefore, we set our excitation spectrum to record fluorescence at $520 \mathrm{~nm}$. As previously shown, our results revealed minimal fluorescence of bilirubin alone in the absence of albumin (Figure 1A). In the presence of albumin, there is a significant shift in relative fluorescence units (RFU), with the maximum emission reported at an excitation wavelength of $465 \mathrm{~nm}$, as reported by us and others $[9,20]$. Biliverdin, in the presence of albumin, also has a shift in RFUs compared to no albumin, indicating that it is also binding to albumin but with a peak at $440 \mathrm{~nm}$. The bilirubin-bound albumin had a 2-fold area under the curve (AUC) greater autofluoresce when compared to biliverdin-bound albumin. The excitation wavelength for bilirubin-bound albumin was set at $465 \mathrm{~nm}$ for subsequent emission spectra. The emission spectra in the $350-480 \mathrm{~nm}$ range for bilirubin with and without albumin recapitulates the previously published data that albumin is necessary for bilirubin to autofluoresce $[9,20]$. We also found that PPAR $\alpha$ ligands WY 14,643 and fenofibrate had no fluorescent activity with or without albumin.

A

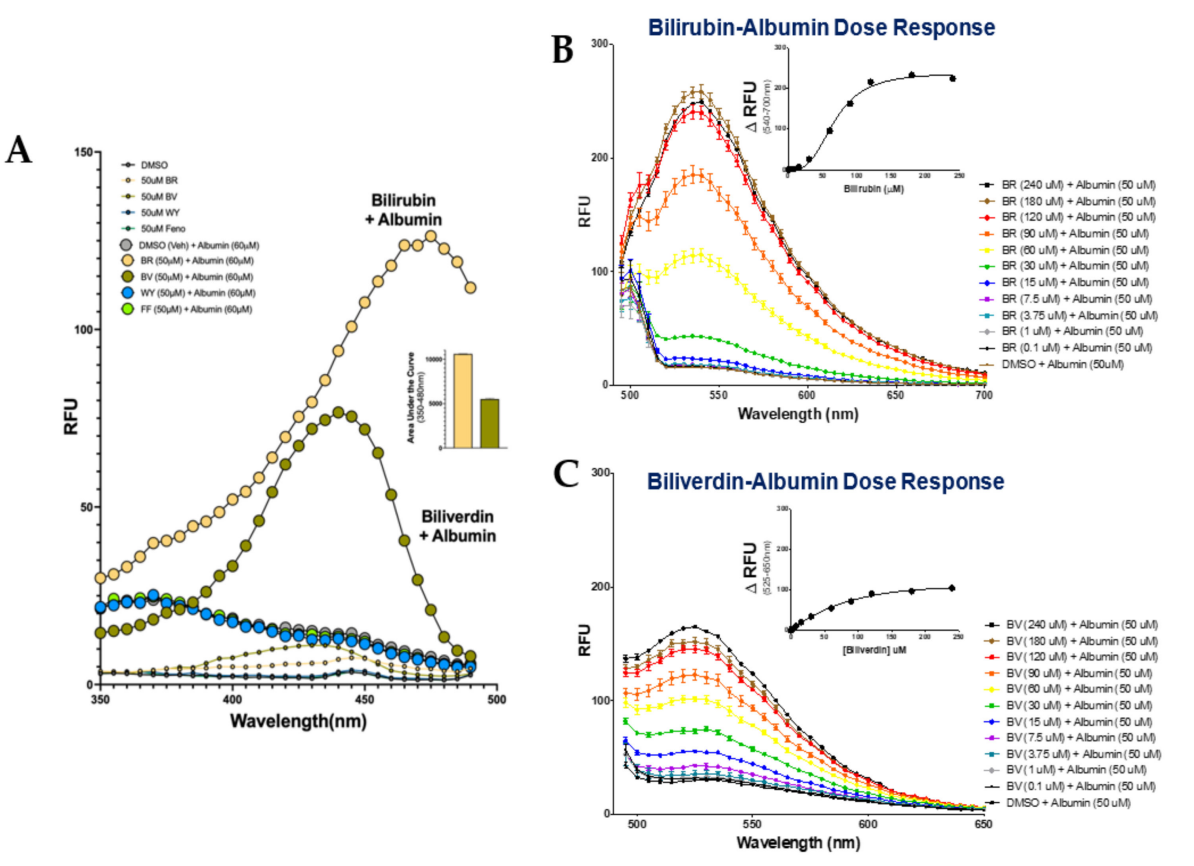

Figure 1. Bilirubin and biliverdin autofluoresce when bound to albumin. (A) Bilirubin and biliverdin binding to albumin emission at $520 \mathrm{~nm}(n=3)$. (B) Bilirubin-bound albumin dose-response curves excited at $465 \mathrm{~nm}(n=3) ; \Delta$ RFU was calculated at 540-700 nm. (C) Biliverdin-bound albumin dose-response curves excited at $440 \mathrm{~nm}(n=3 ; \Delta R F U$ was calculated at 525-650nm. BR, bilirubin; BV. biliverdin; WY, WY 14,643; FF, fenofibrate; DMSO, vehicle. 
We next determined the binding of bilirubin to albumin via fluorescence using the $465 \mathrm{~nm}$ excitation measuring in the 540-700 $\mathrm{nm}$ as previously shown [9]. An increasing dose of bilirubin was used in the presence of albumin to determine the maximal shift in autofluorescence. A Gaussian curve was fit to each spectrum, revealing a dose-dependent increase in fluorescence (Figure 1B). As in previous studies, the maximum fluorescence $\left(\mathrm{F}_{\max }\right)$ was recorded and defined as the peak fluorescence intensity within the emission spectra for each condition [9]. To create a dose-response curve, $\Delta R F U$ values were calculated by subtracting the $\mathrm{F}_{\max }$ recorded with bilirubin alone at a given concentration from the $F_{\max }$ at the same concentration but in the presence of albumin. These values were used as the $\triangle \mathrm{RFU}$ for subsequent analysis to determine the specific binding. For affinity analysis, the specific binding $F_{\max }$ per condition was plotted against the concentration of bilirubin, and a non-linear line was fit to the graph. The disassociation constant $\left(\mathrm{K}_{\mathrm{d}}\right)$ was calculated using the fitted line and was determined to be the concentration in which half of the maximum fluorescence was achieved. A line fit to the $F_{\max }$ at each concentration revealed a $\mathrm{K}_{\mathrm{d}}$ value of $11.10 \mu \mathrm{M}$ for bilirubin-bound albumin. To further analyze the biliverdin-bound albumin autofluorescence, we measured fluorescence using the $440 \mathrm{~nm}$ excitation over the 525-650 $\mathrm{nm}$ spectra as these were the peak values for biliverdin in Figure 1A. The results in Figure 1C show a dose-dependent increase in fluorescence for biliverdin bound to albumin.

\subsection{Bilirubin Fluoresces when Bound to PPAR $\alpha$}

Many studies have exploited the property of bilirubin to autofluoresce when bound to albumin, and recently we showed that this fluorescent capability could be extended to study bilirubin's interactions with other proteins [20]. Given that bilirubin was shown to bind directly to PPAR $\alpha$, we wanted to determine at what level autofluoresce excitation occurs for bilirubin-bound PPAR $\alpha$. We used purified histidine-tagged PPAR $\alpha$ (His-PPAR $\alpha)$, bilirubin and vehicle (DMSO) alone, and a combination of PPAR $\alpha$ and bilirubin and measured emission set at $520 \mathrm{~nm}$. The maximal excitation fluorescence of bilirubin bound to PPAR $\alpha$ was found to be at $450 \mathrm{~nm}$ (Figure 2A). Comparing the PPAR $\alpha$-bound bilirubin to albuminbound in Figure 1A, there was a shift in PPAR $\alpha$-bilirubin from maximal fluorescence of 465 to $455 \mathrm{~nm}$ for PPAR $\alpha$. We incubated PPAR $\alpha$ with increasing amounts of bilirubin and recorded the emission at its max peak. Therefore, we set up the excitation of the bilirubin-PPAR $\alpha$ complex at $455 \mathrm{~nm}$ and measured the 530-700 nm wavelength. Our results showed a significant increase in bilirubin-induced fluorescent activity with an increasing bilirubin concentration (Figure 2B). The $\triangle \mathrm{RFU}$ for each concentration was plotted against the concentration of bilirubin, with a line of best fit, revealing a $\mathrm{K}_{\mathrm{d}}$ value of $5.13 \mu \mathrm{M}$. Of importance, the level of RFU autofluorescence observed in albumin-bound bilirubin compared to PPAR $\alpha$-bound bilirubin, the protein level was significantly higher at $50 \mu \mathrm{M}$ albumin compared to $7.8 \mu \mathrm{M} \operatorname{PPAR} \alpha$. Overall, these data show that bilirubin directly binds to PPAR $\alpha$. However, whether bilirubin binds directly to the LBD cannot be determined from these data. Therefore, we performed site-specific mutagenesis to determine binding areas.

\subsection{Bilirubin Requires Distinct Amino Acids to Maximize Binding to PPAR $\alpha$}

PPAR $\alpha$ has a single low-fidelity ligand-binding pocket. Our previously published in silico docking analysis revealed several predicted residues that bilirubin might interact in the PPAR $\alpha$ LBD by hydrogen bonding to stabilize binding [3]. Therefore, we explored how mutating the predicted hydrogen bonding sites of interaction might affect bilirubin's binding capacity. Mutations were made in our histidine-tagged WT PPAR $\alpha$ (His-PPAR $\alpha$ ) vector via the substitution of glycine at the following sites: Threonine 283 (T283G), methionine 330 (M330G), and alanine 333 (A333G). We measured the emission set at $540 \mathrm{~nm}$ for WT PPAR $\alpha$ and mutants. The results show a reduction in the maximal fluorescence between the mutants and WT (Figure 3A). The maximal excitation fluorescence of bilirubin bound to $\operatorname{PPAR} \alpha$ was found to be at $455 \mathrm{~nm}$, which was used in the next analysis to determine which 
amino acids are bound by bilirubin. Using the WT PPAR $\alpha$ and mutants at an excitation of $455 \mathrm{~nm}$, the wavelengths were measured in 530-700 nm spectra, and the $\triangle R F U$ was calculated for subsequent analysis to determine the specific binding (Figure 3B). There was a significant decrease in bilirubin-induced fluorescence for PPAR $\alpha$ mutants T283G (vs. WT, $p<0.05$ ) and A333G (vs. WT, $p<0.01$ ). There was no significant decrease in fluorescence between the WT and PPAR $\alpha$ mutant M330G ( $p=0.3673)$.
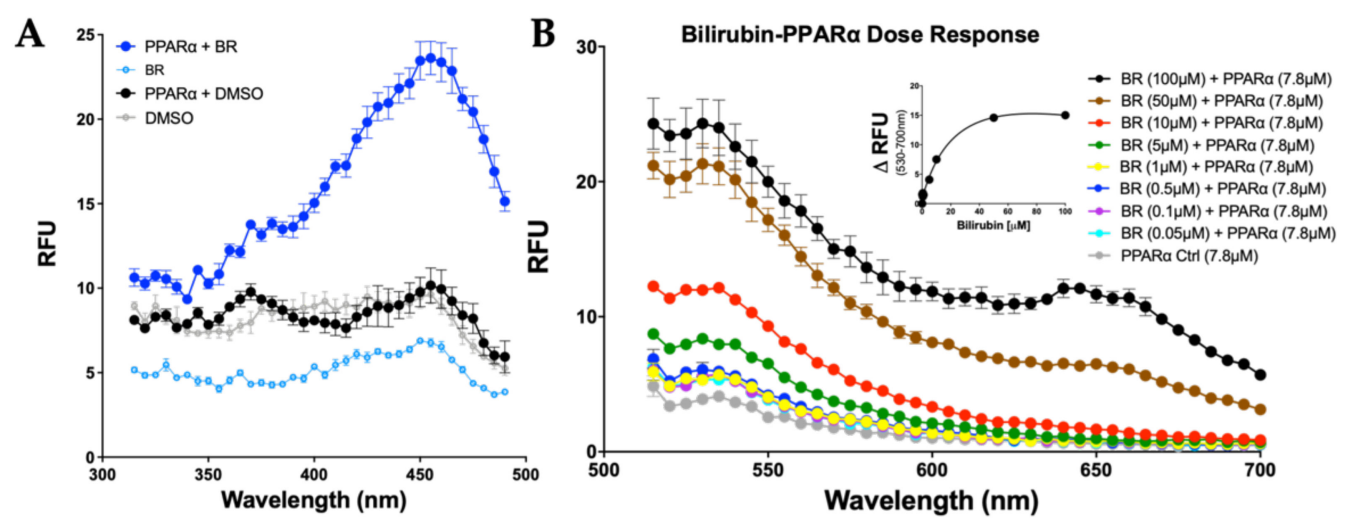

Figure 2. Bilirubin bound to PPAR $\alpha$ autofluoresces. (A) Bilirubin binding to PPAR $\alpha$ was measured at emission at $540 \mathrm{~nm}$ $(n=3)$. (B) Bilirubin-bound PPAR $\alpha$ dose-response curves excited at $455 \mathrm{~nm}(n=3)$; $\Delta$ RFU was calculated at 530-700 nm. $\mathrm{BR}$, bilirubin; DMSO, vehicle.
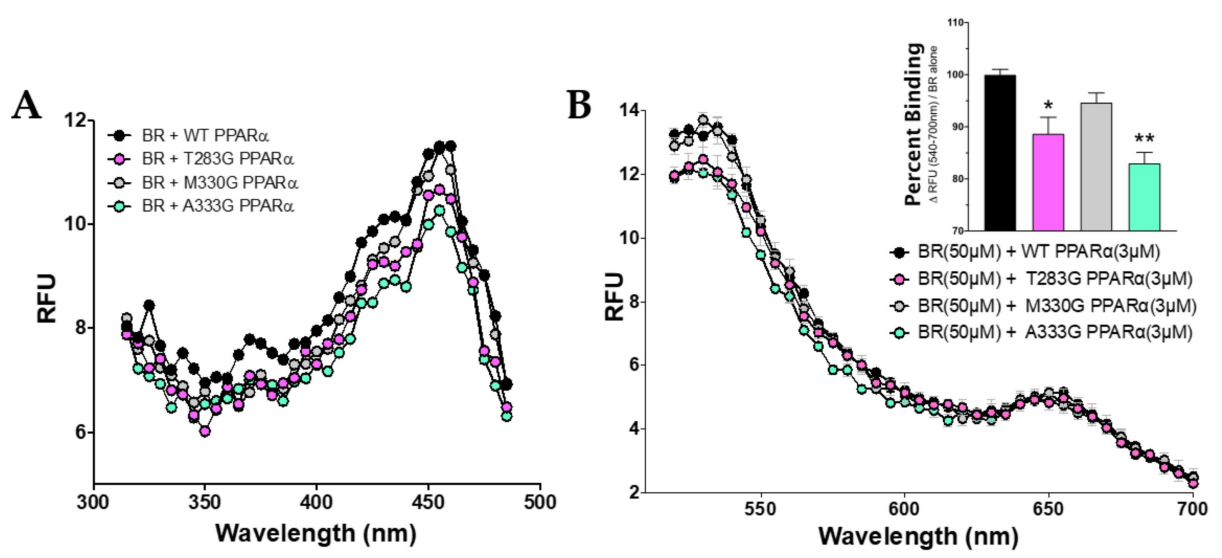

Figure 3. Amino acids in the PPAR $\alpha$ ligand-binding domain that bilirubin binds to induce autofluoresce. (A) Bilirubin binding to WT PPAR $\alpha$ and ligand-binding mutants T283G PPAR $\alpha$, M330G PPAR $\alpha$, and A333G PPAR $\alpha$ emission at $540 \mathrm{~nm}(n=3)$. (B) Bilirubin-bound PPAR $\alpha$ WT and mutants excited at $455 \mathrm{~nm}(n=3)$; percent binding $=\left[(\Delta \mathrm{RFU}\right.$ was calculated at $\left.540-700 \mathrm{~nm}) /(\mathrm{BR} \text { alone })^{*} 100\right]$. BR, bilirubin.

\subsection{Specific Binding of Bilirubin to PPARs}

Previously, we have shown that bilirubin did not bind PPAR $\gamma$ [20], which here we wanted to determine whether there might be an interaction that induces autofluoresce. Measurement of the emission at $540 \mathrm{~nm}$ or excitation at $455 \mathrm{~nm}$ and analysis of the 510 to $700 \mathrm{~nm}$ spectra for bilirubin and PPAR $\gamma$ showed no autofluoresce as was observed with $\operatorname{PPAR} \alpha$ (Figure 4A,B). We have previously shown that PPAR $\alpha$-bound bilirubin competed for the LBD with fenofibrate [20]. To determine how bilirubin and fenofibrate were affected by the site-specific mutants during the competition binding, we performed the same assay described in Figure 3. The results show that bilirubin and fenofibrate compete for the PPAR $\alpha$ LBD and that the Met330 site is more relevant for fenofibrate binding (Figure 5A,B). 

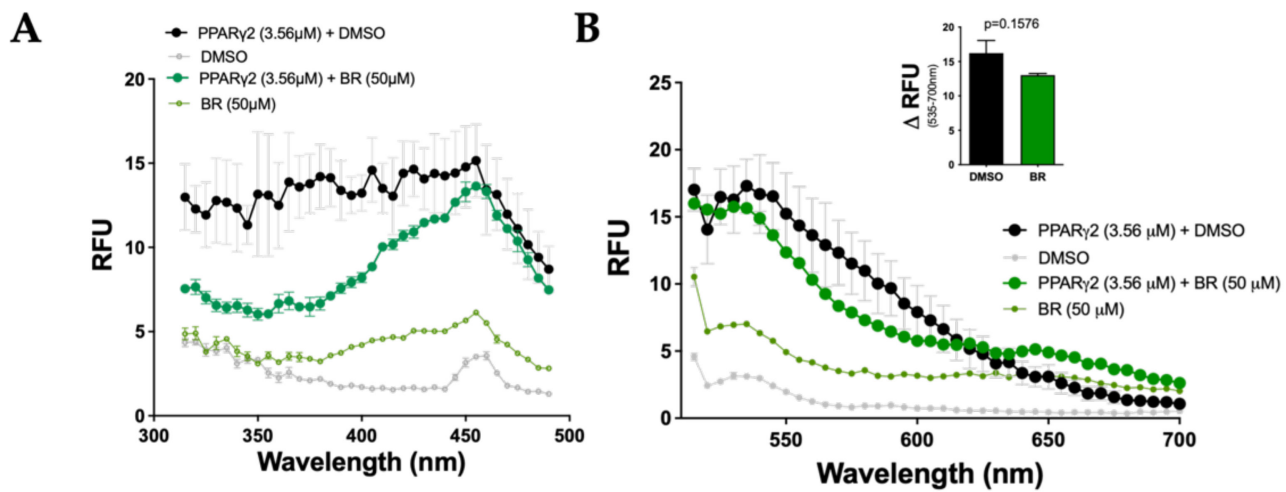

Figure 4. Bilirubin does not autofluoresce with PPAR $\gamma 2$. (A) Bilirubin binding to PPAR $\gamma 2$ was measured at emission at $540 \mathrm{~nm}(n=3)$. (B) Bilirubin and PPAR $\gamma 2$ were excited at $455 \mathrm{~nm}$ and spectra were measured at 510 to $700 \mathrm{~nm}(n=3) ; \Delta \mathrm{RFU}$ was calculated at 535-700 nm. BR, bilirubin; DMSO, vehicle.

A

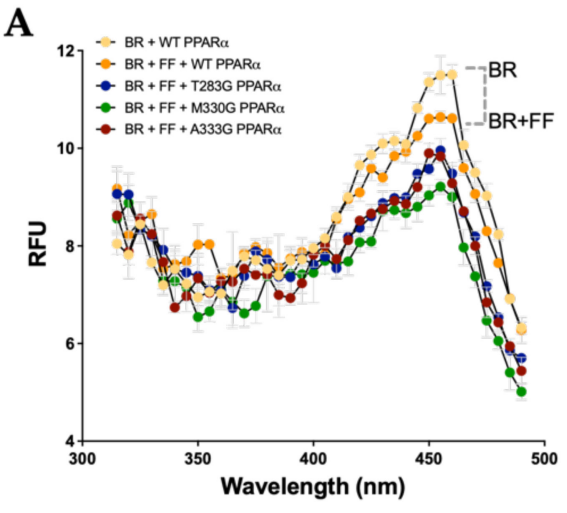

B

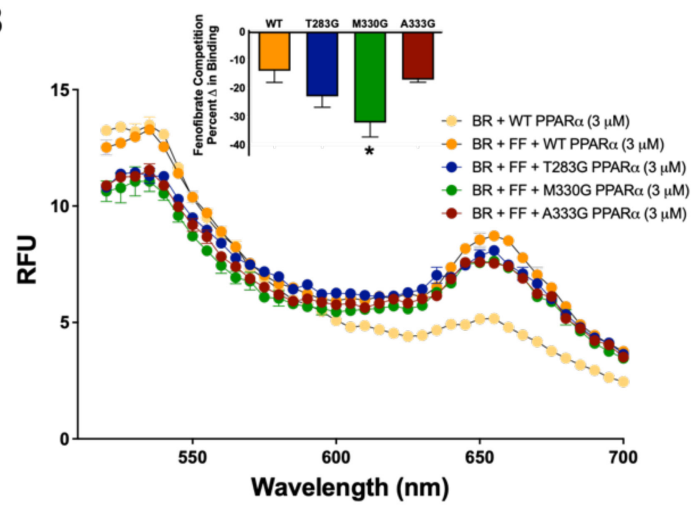

Figure 5. Bilirubin competes with fenofibrate for binding the PPAR $\alpha$ ligand-binding domain. (A) Bilirubin binding to WT PPAR $\alpha$ and ligand-binding mutants T283G PPAR $\alpha$, M330G PPAR $\alpha$, and A333G PPAR $\alpha$ emission at $540 \mathrm{~nm}(n=3)$. (B) Bilirubin-bound PPAR $\alpha$ WT and mutants excited at $455 \mathrm{~nm}(n=3)$; percent binding $=[(\Delta \mathrm{RFU}$ was calculated at 540-700 nm)/(BR alone $\left.{ }^{*} 100\right]$ and then BR-BR + FF for each mutant. BR, bilirubin; FF, fenofibrate.

\section{Discussion}

The concept that bilirubin may function as a hormone by directly binding to the PPAR $\alpha$ nuclear receptor is a new concept, shifting the thinking about this 'old molecule' $[19,21-23]$. Recent work using bilirubin nanoparticles has shown that this is a fat-busting hormone that reduces body weight and adipocyte size in obese mice [20] and fatty liver disease while not causing liver dysfunction [6]. Studies have revealed an association with lower incidences of cardiovascular events and metabolic syndrome in patients with mildly elevated bilirubin levels $[24,25]$. These posit that there is more to be known about this old molecule.

In silico docking analysis from our previous work revealed potential sites that bilirubin may interact in the PPAR $\alpha$ ligand-binding pocket [3]. Here, we wanted to determine whether these sites were essential by mutating the amino acid sites (T283G, M330G, and A333G) to determine they are necessary for the interaction of bilirubin with the PPAR $\alpha$ LBD. Our results reveal compelling data that detail interactions between PPAR $\alpha$ and bilirubin via their autofluorescent emission upon excitation in the presence of PPAR $\alpha$ versus with either alone. Our previous work showed that bilirubin induced transcriptional activity of the GAL4-PPAR $\alpha$ LBD construct with an $\mathrm{EC}_{50}$ of $9.0 \mu \mathrm{M}$ [6], which in this study using a different technique found that the $\mathrm{K}_{\mathrm{d}}$ value of bilirubin-bound PPAR $\alpha$ was $5.13 \mu \mathrm{M}$. We also found that bilirubin did not drive the transcriptional activity of the other PPAR isoforms, PPAR $\gamma$ or PPAR $\beta / \delta[6]$. Here, we found that autofluoresce was not observed between PPAR $\gamma$ and bilirubin, indicating no binding, which supports our previous finding that bilirubin did not drive the transcriptional activity of this isoform. The results from 
this study reveal the importance of the amino acid residues for the predicted binding sites. We found that mutational analysis of T283 and A333 of the PPAR $\alpha$ LBD showed significantly reduced bilirubin binding, reductions of $11.4 \%$ and $17.0 \%$, respectively. We also found that fenofibrate and bilirubin compete for the PPAR $\alpha$ binding site and that the Met330 site might be essential for fenofibrate binding. A study by Yamamoto et al. confirmed that Met330 is a critical site for fenofibrate binding in the PPAR $\alpha$ LBD to induce transcriptional activity [26]. Their investigation also showed that another PPAR $\alpha$ ligand, pemafibrate, was not affected by mutational analysis of the Met330 site. These suggest that the differential control of specific gene pathways might depend on ligand binding with particular amino acids that cause a conformation change in the PPAR $\alpha$ structure that induces pathway-specific patterns. Furthermore, bilirubin and its light-reactive form, lumirubin, have recently been shown by others to activate PPAR $\alpha$ transcriptional activity in HepG2 human hepatocytes [27]. Their findings showed that bilirubin and lumirubin had diverse gene regulatory patterns, suggesting that different amino acids might regulate the binding of these molecules in the PPAR $\alpha$ LBD.

The link between bilirubin and cardiometabolic disease has been suggested to exist via the interaction of bilirubin and PPAR $\alpha$ [21]. While this study confirms a direct interaction between bilirubin and amino acids in the LBD, previous studies have shown bilirubin to positively influence metabolic status via PPAR $\alpha$. Bilirubin's role in metabolism is poorly understood. Our previous studies showed a loss in bilirubin mediated weight loss in the absence of PPAR $\alpha$ [3]. There may be interactions of bilirubin with other proteins outside of PPAR $\alpha$. However, our recent study showed that bilirubin-induced transcriptome responses were $95 \%$ PPAR $\alpha$ dependent [28], indicating that this nuclear receptor might be primarily responsible for its induction of gene transcripts. However, more work is needed to build upon this conclusion.

PPAR $\alpha$ has been shown to alter gene expression for various cellular functions but is widely studied for its impact in increasing lipid metabolism. PPAR $\alpha$ hepatocytespecific knockout mice have a characteristically increased hepatic lipid storage [29], and $\mathrm{ob} / \mathrm{ob}$ leptin-deficient obese mice have reduced plasma bilirubin and hepatic PPAR $\alpha$ [30]. Adipocytes and hepatocytes treated with bilirubin had a significantly lower level of lipid accumulation compared to the control-treated cells [3,31]. The bilirubin-induced regulation of PPAR $\alpha$ may help to understand clinical phenotypes in patients with lower bilirubin levels [19]. Mutations of the PPAR $\alpha$ LBD reinforce our previous in silico-predicted amino acid residues that might stabilize binding with bilirubin [3]. The loss of this stable interaction confirms bilirubin's conformational stringency in binding to PPAR $\alpha$. This could explain why biliverdin, the "prodrug" of bilirubin, did not show strong binding to PPAR $\alpha$ [3]. Hence, a hepatocyte-specific knockout of biliverdin reductase A (BVRA), the enzyme responsible for producing bilirubin [32], causes severe hepatic steatosis and glucose intolerance [33]. Mice with an adipose-specific BVRA KO showed increased adipocyte size and reduced mitochondria [34]. On the other hand, bilirubin nanoparticle treatment in obese mice decreased white adipose tissue (WAT) size and increased mitochondria number [20]. These imply that possibly inducing heme oxygenase or BVRA might improve adiposity by increasing plasma bilirubin [35]. This concept is supported in a study showing that high-aerobic-capacity running rats had significantly higher plasma bilirubin and increased hepatic BVRA and PPAR $\alpha$ than the low-running-capacity obese animals [36].

\section{Conclusions}

The data presented here clearly reveal the interactions of bilirubin with the PPAR $\alpha$ LBD. These interactions reveal the potential of bilirubin in modulating cellular processes and ultimately enhancing metabolic potential. Studies have indicated lesser incidences in cardiovascular events and metabolic syndrome in patients with mildly elevated bilirubin levels [24,25], and mice with hyperbilirubinemia are protected from adiposity [6,37]. Further studies are needed to highlight the effect of bilirubin in mediating metabolic potential compared to other known ligands of PPAR $\alpha$ such as the fibrates. Unveiling the role of 
bilirubin as a metabolic hormone posits that the old molecule is a potential new agent for addressing the metabolic syndrome.

Author Contributions: Conceptualization, D.M.G. and T.D.H.J.; methodology, D.M.G.; validation, D.M.G. and S.H.H.; formal analysis, D.M.G., S.H.H., and Z.A.K.; investigation, D.M.G., S.H.H., and Z.A.K.; resources, T.D.H.J.; data curation, D.M.G.; writing—original draft preparation, D.M.G.; writing-review and editing, D.M.G.; visualization, D.M.G., S.H.H., and T.D.H.J.; supervision, T.D.H.J.; project administration, T.D.H.J.; funding acquisition, T.D.H.J. All authors have read and agreed to the published version of the manuscript.

Funding: This work was supported by the National Institutes of Health 1R01DK121797 (T.D.H.J.). The content is solely the responsibility of the authors and does not necessarily represent the official views of the National Institutes of Health.

Institutional Review Board Statement: Not applicable.

Informed Consent Statement: Not applicable.

Data Availability Statement: The data presented in this study are available on request from the corresponding author.

Acknowledgments: The authors gratefully acknowledge Paul Erhardt and Jeffrey Sarver at the University of Toledo for their assistance in helping with the initial setup of the experiments and use of the equipment for the analysis.

Conflicts of Interest: The authors declare no conflict of interest.

\section{References}

1. Menendez-Gutierrez, M.P.; Roszer, T.; Ricote, M. Biology and therapeutic applications of peroxisome proliferator- activated receptors. Curr. Top. Med. Chem. 2012, 12, 548-584. [CrossRef]

2. Grygiel-Górniak, B. Peroxisome proliferator-activated receptors and their ligands: Nutritional and clinical implications-a review. Nutr. J. 2014, 13, 17. [CrossRef] [PubMed]

3. Stec, D.E.; John, K.; Trabbic, C.J.; Luniwal, A.; Hankins, M.W.; Baum, J.; Hinds, T.D., Jr. Bilirubin Binding to PPAR $\alpha$ Inhibits Lipid Accumulation. PLoS ONE 2016, 11, e0153427. [CrossRef]

4. Chiu, M.; McBeth, L.; Sindhwani, P.; Hinds, T.D. Deciphering the Roles of Thiazolidinediones and PPAR $\gamma$ in Bladder Cancer. PPAR Res. 2017, 2017, 1-9. [CrossRef]

5. Hinds, T.D.; Stechschulte, L.A.; Cash, H.A.; Whisler, D.; Banerjee, A.; Yong, W.; Khuder, S.S.; Kaw, M.K.; Shou, W.; Najjar, S.M.; et al. Protein Phosphatase 5 Mediates Lipid Metabolism through Reciprocal Control of Glucocorticoid Receptor and Peroxisome Proliferator-activated Receptor- $\gamma$ (PPAR $\gamma$ ). J. Biol. Chem. 2011, 286, 42911-42922. [CrossRef]

6. Hinds, T.D.J.; Creeden, J.F.; Gordon, D.M.; Stec, D.F.; Donald, M.C.; Stec, D.E. Bilirubin Nanoparticles Reduce Diet-Induced Hepatic Steatosis, Improve Fat Utilization, and Increase Plasma $\beta$-Hydroxybutyrate. Front. Pharmacol. 2020, 11, 594574. [CrossRef] [PubMed]

7. Lamola, A.A.; Russo, M. Fluorescence excitation spectrum of bilirubin in blood: A model for the action spectrum for phototherapy of neonatal jaundice. Photochem. Photobiol. 2013, 90, 294-296. [CrossRef] [PubMed]

8. McDonagh, A.F.; Palma, L.A.; Lightner, D.A. Phototherapy for neonatal jaundice. Stereospecific and regioselective photoisomerization of bilirubin bound to human serum albumin and NMR characterization of intramolecularly cyclized photoproducts. J. Am. Chem. Soc. 1982, 104, 6867-6869. [CrossRef]

9. Croce, A.C.; Ferrigno, A.; Santin, G.; Vairetti, M.; Bottiroli, G. Bilirubin: An autofluorescence bile biomarker for liver functionality monitoring. J. Biophotonics 2013, 7, 810-817. [CrossRef]

10. Petersen, C.E.; Ha, C.-E.; Harohalli, K.; Feix, J.B.; Bhagavan, N.V. A Dynamic Model for Bilirubin Binding to Human Serum Albumin. J. Biol. Chem. 2000, 275, 20985-20995. [CrossRef]

11. Lightner, D.A.; Wooldridge, T.A.; McDonagh, A.F. Photobilirubin: An early bilirubin photoproduct detected by absorbance difference spectroscopy. Proc. Natl. Acad. Sci. USA 1979, 76, 29-32. [CrossRef]

12. Greene, B.I.; Lamola, A.A.; Shank, C.V. Picosecond primary photoprocesses of bilirubin bound to human serum albumin. Proc. Natl. Acad. Sci. USA 1981, 78, 2008-2012. [CrossRef]

13. Plavskii, V.Y.; Mostovnikov, V.A.; Mostovnikova, G.R.; Tret'Yakova, A.I. Spectral fluorescence and polarization characteristics of Z,Z-bilirubin IX $\alpha$. J. Appl. Spectrosc. 2007, 74, 120-132. [CrossRef]

14. Hostetler, H.A.; Petrescu, A.D.; Kier, A.B.; Schroeder, F. Peroxisome Proliferator-activated Receptor $\alpha$ Interacts with High Affinity and Is Conformationally Responsive to Endogenous Ligands. J. Biol. Chem. 2005, 280, 18667-18682. [CrossRef] [PubMed]

15. Kliewer, S.A.; Sundseth, S.S.; Lehmann, J.M.; Jones, S.A.; Brown, P.J.; Wisely, G.B.; Koble, C.S.; Devchand, P.; Wahli, W.; Willson, T.M.; et al. Fatty acids and eicosanoids regulate gene expression through direct interactions with peroxisome proliferatoractivated receptors and. Proc. Natl. Acad. Sci. USA 1997, 94, 4318-4323. [CrossRef] 
16. Lin, Q.; Ruuska, S.E.; Shaw, N.S.; Dong, D.; Noy, N. Ligand Selectivity of the Peroxisome Proliferator-Activated Receptor $\alpha+$. Biochemistry 1999, 38, 185-190. [CrossRef] [PubMed]

17. Kumagai, A.; Ando, R.; Miyatake, H.; Greimel, P.; Kobayashi, T.; Hirabayashi, Y.; Shimogori, T.; Miyawaki, A. A BilirubinInducible Fluorescent Protein from Eel Muscle. Cell 2013, 153, 1602-1611. [CrossRef]

18. Adeosun, S.O.; Moore, K.H.; Lang, D.M.; Nwaneri, A.C.; Hinds, J.T.; Stec, D.E. A Novel Fluorescence-Based Assay for the Measurement of Biliverdin Reductase Activity. React. Oxyg. Spec. 2018, 5, 35-45. [CrossRef] [PubMed]

19. Creeden, J.F.; Gordon, D.M.; Stec, D.E.; Hinds, T.D. Bilirubin as a metabolic hormone: The physiological relevance of low levels. Am. J. Physiol. Metab. 2021, 320, E191-E207. [CrossRef]

20. Gordon, D.M.; Neifer, K.L.; Hamoud, A.-R.A.; Hawk, C.F.; Nestor-Kalinoski, A.L.; Miruzzi, S.A.; Morran, M.P.; Adeosun, S.O.; Sarver, J.G.; Erhardt, P.W.; et al. Bilirubin remodels murine white adipose tissue by reshaping mitochondrial activity and the coregulator profile of peroxisome proliferator-activated receptor $\alpha$. J. Biol. Chem. 2020, 295, 9804-9822. [CrossRef] [PubMed]

21. HindsJr, T.D.; Stec, D.E. Bilirubin, a Cardiometabolic Signaling Molecule. Hypertension 2018, 72, 788-795. [CrossRef] [PubMed]

22. Hamoud, A.-R.; Weaver, L.; Stec, D.E.; Hinds, T.D. Bilirubin in the Liver-Gut Signaling Axis. Trends Endocrinol. Metab. 2018, 29, 140-150. [CrossRef] [PubMed]

23. Hinds, T.D.; Stec, D.E. Bilirubin Safeguards Cardiorenal and Metabolic Diseases: A Protective Role in Health. Curr. Hypertens. Rep. 2019, 21, 1-7. [CrossRef] [PubMed]

24. Choi, S.; Yun, K.; Choi, H. Relationships between serum total bilirubin levels and metabolic syndrome in Korean adults. Nutr. Metab. Cardiovasc. Dis. 2013, 23, 31-37. [CrossRef]

25. Vítek, L.; Jirsa, M.; Brodanová, M.; Kaláb, M.; Mareček, Z.; Danzig, V.; Novotný, L.; Kotal, P. Gilbert syndrome and ischemic heart disease: A protective effect of elevated bilirubin levels. Atherosclerosis 2002, 160, 449-456. [CrossRef]

26. Yamamoto, Y.; Takei, K.; Arulmozhiraja, S.; Sladek, V.; Matsuo, N.; Han, S.-I.; Matsuzaka, T.; Sekiya, M.; Tokiwa, T.; Shoji, M.; et al. Molecular association model of PPAR $\alpha$ and its new specific and efficient ligand, pemafibrate: Structural basis for SPPARM $\alpha$. Biochem. Biophys. Res. Commun. 2018, 499, 239-245. [CrossRef]

27. Dvořák, A.; Pospíšilová, K.; Žižžlová, K.; Capková, N.; Muchová, L.; Vecka, M.; Vrzáčková, N.; Křížová, J.; Zelenka, J.; Vítek, L. The Effects of Bilirubin and Lumirubin on Metabolic and Oxidative Stress Markers. Front. Pharmacol. 2021, 12, 567001. [CrossRef]

28. Gordon, D.M.; Blomquist, T.M.; Miruzzi, S.A.; McCullumsmith, R.; Stec, D.E.; Hinds, T.D. RNA sequencing in human HepG2 hepatocytes reveals PPAR- $\alpha$ mediates transcriptome responsiveness of bilirubin. Physiol. Genom. 2019, 51, 234-240. [CrossRef]

29. Stec, D.E.; Gordon, D.M.; Hipp, J.A.; Hong, S.; Mitchell, Z.L.; Franco, N.R.; Robison, J.W.; Anderson, C.D.; Stec, D.F.; Hinds, T.D., Jr. The loss of hepatic PPARalpha promotes inflammation and serum hyperlipidemia in diet-induced obesity. Am. J. Physiol. Regul. Integr. Comp. Physiol. 2019, 317, R733-R745. [CrossRef]

30. Hinds, T.D., Jr.; Sodhi, K.; Meadows, C.; Fedorova, L.; Puri, N.; Kim, D.H.; Peterson, S.J.; I Shapiro, J.; Abraham, N.G.; Kappas, A. Increased HO-1 levels ameliorate fatty liver development through a reduction of heme and recruitment of FGF21. Obesity 2014, 22, 705-712. [CrossRef]

31. Gordon, D.M.; Adeosun, S.O.; Ngwudike, S.I.; Anderson, C.D.; Hall, J.E.; Hinds, T.D.; Stec, D.E. CRISPR Cas9-mediated deletion of biliverdin reductase A (BVRA) in mouse liver cells induces oxidative stress and lipid accumulation. Arch. Biochem. Biophys. 2019, 672, 108072. [CrossRef] [PubMed]

32. O’Brien, L.; Hosick, P.A.; John, K.; Stec, D.E.; Hinds, T.D. Biliverdin reductase isozymes in metabolism. Trends Endocrinol. Metab. 2015, 26, 212-220. [CrossRef] [PubMed]

33. Hinds, T.D., Jr.; Burns, K.A.; Hosick, P.A.; McBeth, L.; Nestor-Kalinoski, A.; Drummond, H.A.; AlAmodi, A.A.; Hankins, M.W.; Heuvel, J.P.V.; Stec, D.E. Biliverdin Reductase A Attenuates Hepatic Steatosis by Inhibition of Glycogen Synthase Kinase (GSK) $3 \beta$ Phosphorylation of Serine 73 of Peroxisome Proliferator-activated Receptor (PPAR) $\alpha$. J. Biol. Chem. 2016, 291, 25179-25191. [CrossRef] [PubMed]

34. Stec, D.E.; Gordon, D.M.; Nestor-Kalinoski, A.L.; Donald, M.C.; Mitchell, Z.L.; Creeden, J.F.; Hinds, J.T.D. Biliverdin Reductase A (BVRA) Knockout in Adipocytes Induces Hypertrophy and Reduces Mitochondria in White Fat of Obese Mice. Biomolecules 2020, 10, 387. [CrossRef] [PubMed]

35. Stec, D.E.; Hinds, J.T.D. Natural Product Heme Oxygenase Inducers as Treatment for Nonalcoholic Fatty Liver Disease. Int. J. Mol. Sci. 2020, 21, 9493. [CrossRef] [PubMed]

36. Hinds, J.T.D.; Creeden, J.F.; Gordon, D.M.; Spegele, A.C.; Britton, S.L.; Koch, L.G.; Stec, D.E. Rats Genetically Selected for High Aerobic Exercise Capacity Have Elevated Plasma Bilirubin by Upregulation of Hepatic Biliverdin Reductase-A (BVRA) and Suppression of UGT1A1. Antioxidants 2020, 9, 889. [CrossRef] [PubMed]

37. Hinds, T.D., Jr.; Hosick, P.A.; Hankins, M.W.; Nestor-Kalinoski, A.; Stec, D.E. Mice with hyperbilirubinemia due to Gilbert's Syndrome polymorphism are resistant to hepatic steatosis by decreased serine 73 phosphorylation of PPARalpha. Am. J. Physiol. Endocrinol. Metab. 2017, 312, E244-E252. [CrossRef] 